\title{
Donald Iverson, PhD DSc(Hon) (1946-2016)
}

\author{
Lawrence W. Green ${ }^{1} \cdot$ Larry A. Green $^{2} \cdot$ Barry Portnoy $^{3} \cdot$ Rob Sanson Fisher $^{4}$ • \\ Fredrick D. Ashbury ${ }^{5}$
}

Published online: 21 July 2016

(C) Springer-Verlag Berlin Heidelberg 2016

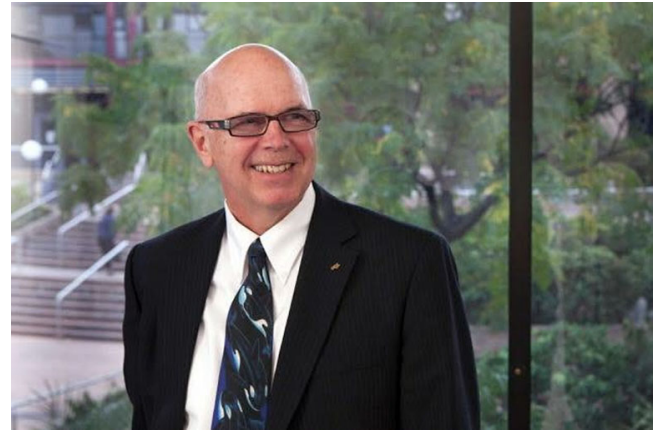

Birth: November 17, 1945, Winnipeg, Canada.

On March 18, the health promotion, cancer control, and family medicine communities lost a friend, mentor, teacher, and scholar with the passing of Prof. Donald Iverson. His contributions to these fields were significant, broad, and deep.

Don received his $\mathrm{PhD}$ from the University of Oregon, Health Education and Health Behavior in March 1971, and an Honorary Doctor of Science from the University of

Fredrick D. Ashbury

fred.ashbury@viviphicare.com

University of California, San Francisco, CA, USA

University of Colorado, Denver, CO, USA

University of Maryland, College Park, MD, USA

4 University of Newcastle, Sydney, Australia

5 University of Toronto, Toronto, ON, Canada
Waterloo. Donald Iverson's career would be difficult to match. Always committed to improving the quality of care he moved in and out of a variety of professional roles including academia, government, and the private sector. Among his many accomplishments, Don:

- Co-developed the national health promotion program of the US Department of Health and Human Services in the early 1980s;

- Led the development of a curriculum for US family medicine residents to enable them to identify and address unhealthful behaviors in front-line practice;

- Was the first director of the Centre for Behavioral Research and Program Evaluation at the National Cancer Institute of Canada, where he formulated and led the development of a Canada-wide socio-behavioral cancer research network.

- Created Can-Am Health Concepts, a private initiative, to develop workplace health initiatives, monitoring and measurement strategies in collaboration with Health Development Partners of Germany;

- Contributed to the development of primary care practicebased research networks in the USA and Canada. Don was the first research director of the Ambulatory Sentinel Practice Network, which was the first national practicebased network committed to generating evidence-based practice in primary care;

- Designed and led initiatives to facilitate point-of-care decision-making for oncologists and patients that have been integrated into oncology information systems used in cancer practices worldwide;

- Participated actively as a member of many local, national, and international committees in health promotion, health education, cancer screening, and behavioral research; 
- Provided leadership and was responsible for the development, management, and monitoring of cancer screening and cancer prevention programs for all residents in the province of Alberta.

- Contributed to cancer control by exemplary reviews and as a board member of Peak cancer control organizations in Australia

- Co-created the vision for and led the successful development of the Illawarra Health and Medical Research Institute at the University of Wollongong in Australia;

- Formulated the vision for and led the successful development and accreditation of a graduate-level entry medical school at the University of Wollongong and served as its founding Dean;

- Appointed to establish and direct a research institute at Swinburne University in Victoria State, Australia.

Don once said,

"I truly believe moving amongst sectors is incredibly valuable in that it allows/forces one to look at issues from a very different perspective. In my case I was fortunate to have worked at the national (OHIP and NIH) and state (Connecticut) government levels, a national NGO (NCIC) and the private sector (OpTx) as well as a few universities. I learned something in each of these positions, especially from a policy and decision making perspective. I have also concluded that the 'easiest' positions are in universities as the demands, especially time sensitive demands, pale in comparison to those experienced by government employees and in the private sector, and the hours for which they are accountable is minimal. I have spent some time over the past decade trying to understand why places like Singapore, Taiwan, Israel and a few other select countries are doing so well in the discovery-translation-application arena and what I have observed is that they have porous boundaries between universities, government agencies and the private sector."

These insights gave Don his rich perspectives and flexibility to inform all sides of health issues calling upon intersectional collaboration or cooperation. His passion to improve the quality of care and thereby improve patient outcomes was transmitted to a variety of audiences in a logical, careful fashion, often laced with humor and self-deprecation. His enthusiasm for new ideas and an evidence-based approach, willingness to collaborate with any who were committed to improving research or practice in our field served as a model for how a professionals in our field should operate. His warmth and genuineness transcended the usual professional roles and made him one of the more charismatic people in our field. Regardless of his roles, Don possessed "enzymatic effects". He would do all he could to accelerate progress, particularly on tough problems that seemed to be stalled. Don often quietly transferred credit to his colleagues and students, as personal recognition was less important to him. He mentored many who have gone on to exciting and prolific careers in family medicine, health promotion, and cancer control. These skills and commitment are partly reflected in the establishment of the Iverson Health Innovation Research Institute at the Swinburne University in Australia.

Don participated on several journal editorial boards and performed reviews for many others. Supportive Care in Cancer enjoyed Don's presence and contributions to our journal as an editorial consultant, reviewer and an author. During his 7-year tenure on the board, Don reviewed 67 papers. His reviews were thoughtful, and feedback was genuine and encouraging to stimulate authors to provide the highest-quality work to grow our discipline.

Don always found the time to help others spending hours researching options and "listening" to people about their experiences and offering advice when asked.

Sadly, he succumbed to cancer. Even at the very end, Don had advice and suggestions about what is needed to be done to improve the care for those at the end of their lives.

Our sincerest condolences go to his wife Lynne, daughter Amelia, and family. Don's friendship, warmth, commitment, and intellectual flexibility and strength will be missed by many around the world.

from:

Lawrence W. Green, DrPH DSc(Hon)

Larry A. Green, MD

Barry Portnoy, $\mathrm{PhD}$

Rob Sanson Fisher, PhD DSc(Hon)

Fredrick D. Ashbury, $\mathrm{PhD}$ 